\title{
Genetic and evolutionary characterization of RABVs from China using the phosphoprotein gene
}

\author{
Lihua Wang ${ }^{1+}$, Hui $\mathrm{Wu}^{1+}$, Xiaoyan Tao ${ }^{1}$, Hao Li ${ }^{1}$, Simon Rayner ${ }^{2}$, Guodong Liang ${ }^{1}$ and Qing Tang ${ }^{1 *}$
}

\begin{abstract}
Background: While the function of the phosphoprotein (P) gene of the rabies virus (RABV) has been well studied in laboratory adapted RABVs, the genetic diversity and evolution characteristics of the P gene of street RABVs remain unclear. The objective of the present study was to investigate the mutation and evolution of $\mathrm{P}$ genes in Chinese street RABVs.

Results: The P gene of 77 RABVs from brain samples of dogs and wild animals collected in eight Chinese provinces through 2003 to 2008 were sequenced. The open reading frame (ORF) of the P genes was 894 nucleotides (nt) in length, with 85-99\% (80-89\%) amino acid (nucleotide) identity compared with the laboratory RABVs and vaccine strains. Phylogenetic analysis based on the P gene revealed that Chinese RABVs strains could be divided into two distinct clades, and several RABV variants were found to co circulating in the same province. Two conserved (CD1, 2) and two variable $(V D 1,2)$ domains were identified by comparing the deduced primary sequences of the encoded P proteins. Two sequence motifs, one believed to confer binding to the cytoplasmic dynein light chain LC8 and a lysine-rich sequence were conserved throughout the Chinese RABVs. In contrast, the isolates exhibited lower conservation of one phosphate acceptor and one internal translation initiation site identified in the P protein of the rabies challenge virus standard (CVS) strain. Bayesian coalescent analysis showed that the P gene in Chinese RABVs have a substitution rate $\left(3.305 \times 10^{-4}\right.$ substitutions per site per year) and evolution history (592 years ago) similar to values for the glycoprotein $(\mathrm{G})$ and nucleoprotein $(\mathrm{N})$ reported previously.

Conclusion: Several substitutions were found in the P gene of Chinese RABVs strains compared to the laboratory adapted and vaccine strains, whether these variations could affect the biological characteristics of Chinese RABVs need to be further investigated. The substitution rate and evolution history of $P$ gene is similar to $G$ and $N$ gene, combine the topology of phylogenetic tree based on the $P$ gene is similar to the $G$ and $N$ gene trees, indicate that the $P, G$ and $N$ genes are equally valid for examining the phylogenetics of RABVs.
\end{abstract}

Keywords: Rabies virus, Phosphoprotein gene, Genetic diversity, Molecular evolution

\section{Introduction}

Rabies is a lethal neurological disease caused by infection with members of the genus lyssavirus. Eleven distinct lyssavirus species are currently recognized worldwide [1]. In China, only the classical rabies virus (RABV) is known to circulate in dogs, which serve as the principal reservoir and transmitter of rabies to humans and domestic animals $[2,3]$. RABV has a non-segmented negative sense RNA

\footnotetext{
* Correspondence: qtang04@sina.com

${ }^{\dagger}$ Equal contributors

'State Key Laboratory for Infectious Disease Prevention and Control, Institute for Viral Disease Control and Prevention, Chinese Center for Disease Control and Prevention, 155 Changbai St., Changping Dist, Beijing 102206, China Full list of author information is available at the end of the article
}

genome comprised of five genes in the order 3'-N-P-M-GL-5' [4]. The relatively divergent $\mathrm{P}$ gene [5-7] encodes a multifunctional phosphoprotein (P protein) $[8]$ and has been extensively investigated using laboratory adapted RABV strains. Five serine residues of the challenge virus standard (CVS) strain have been identified as phosphate acceptor sites [9]. Also, P is a critical component of the viral polymerase responsible for transcription and replication through its binding to the $\mathrm{N}$ and $\mathrm{L}$ proteins [10-12]. Two independent $\mathrm{N}$ binding sites, one located within amino acids (aa) 66-176 at the N-terminal half of the protein and the other located to amino acids 268-297 within 50 residues of the $\mathrm{C}$-terminus, have been found in the $\mathrm{P}$ protein [10,11]. Via N-P complexes, the nonspecific

\section{Biomed Central}


aggregation of $\mathrm{N}$ can be prevented and can keep $\mathrm{N}$ in a suitable form for specific encapsidation [13]. The short lysine-rich motif FSKKYKF (aa 214-220) is an important component of the $\mathrm{C}$-terminal $\mathrm{N}$ protein binding domain of $\mathrm{P}$ [14]. $\mathrm{P}$ is associated with the genome expression process by acting as an intermediary for the attachment of the $\mathrm{L}$ polymerase core to the N-RNA template [15]. In addition, the first $19 \mathrm{~N}$-terminal residues of $\mathrm{P}$ confer $\mathrm{L}$ protein binding [10]. $\mathrm{P}$ also specifically interacts with many host cell components. It has been reported that the sequence (K/R)XTQT represents a conserved cytoplasmic dynein light chain (LC8) binding motif, an element of the microtubule-associated motors involved in minus-end directed axonal transport, through which it may play some role in viral retrograde transport [16-18]. P interferes with the host's innate immune system through inhibition of the activities of interferon regulatory factor 3 (IRF3) [19] and signal transducer and activator of transcription 1 (STAT1) [20,21], thereby abrogating the cellular type 1 interferon pathway. $\mathrm{P}$ also binds to the promyelocytic leukemia (PML) protein, which has many possible functions in nuclear trafficking, viral defense mechanisms and apoptosis [22], suggesting that P acts an antagonist towards antiviral PML function [23].

Since all functional studies on the RABV P protein have been performed using a limited number of laboratory strains, the relevance of the results to field isolates is unclear. In this study we sequenced the P gene of Chinese RABV street strains collected in most rabies endemic areas of China and investigated the genetic diversity, sequence characteristics and estimated the overall substitution rate of the $\mathrm{P}$ gene. In addition, the phylogeny and evolution history of Chinese RABVs based on $\mathrm{P}$ gene were examined.

\section{Results \\ Length and identity of $P$ gene in Chinese RABV street strains}

77 RABV positive brain specimens were detected by direct fluorescent antibody (DFA) and subjected to RT-PCR for determination of the $\mathrm{P}$ gene of RABV street strains. These specimens were from field captured dogs and ferret badgers in eight provinces which had high (Guangxi, Guizhou and Hunan provinces), middle (Jiangsu and Shandong provinces) and low (Anhui, Shanghai, and Zhejiang provinces) incidences of rabies (Figure 1). The open reading frame (ORF) of the $\mathrm{P}$ gene, corresponding to nt 1514-2407 of the PV strain (M13215), was determined for all 77 RABV isolates. The ORF of the P gene of all Chinese RABVs were 894 nt in length and sequences were submitted to GenBank (HM582519-HM582595). The species of origin, the year of isolation, and geographical location of these sequences are summarized in Table 1.

The P gene of all the Chinese RABVs encodes a 297 amino acid protein identical in length to the $\mathrm{P}$ gene in the PV vaccine strain (M13215). The nucleotide and deduced amino acid sequences were aligned and compared with the sequences of laboratory, street and vaccine strains. Among the 77 Chinese RABVs isolates, the

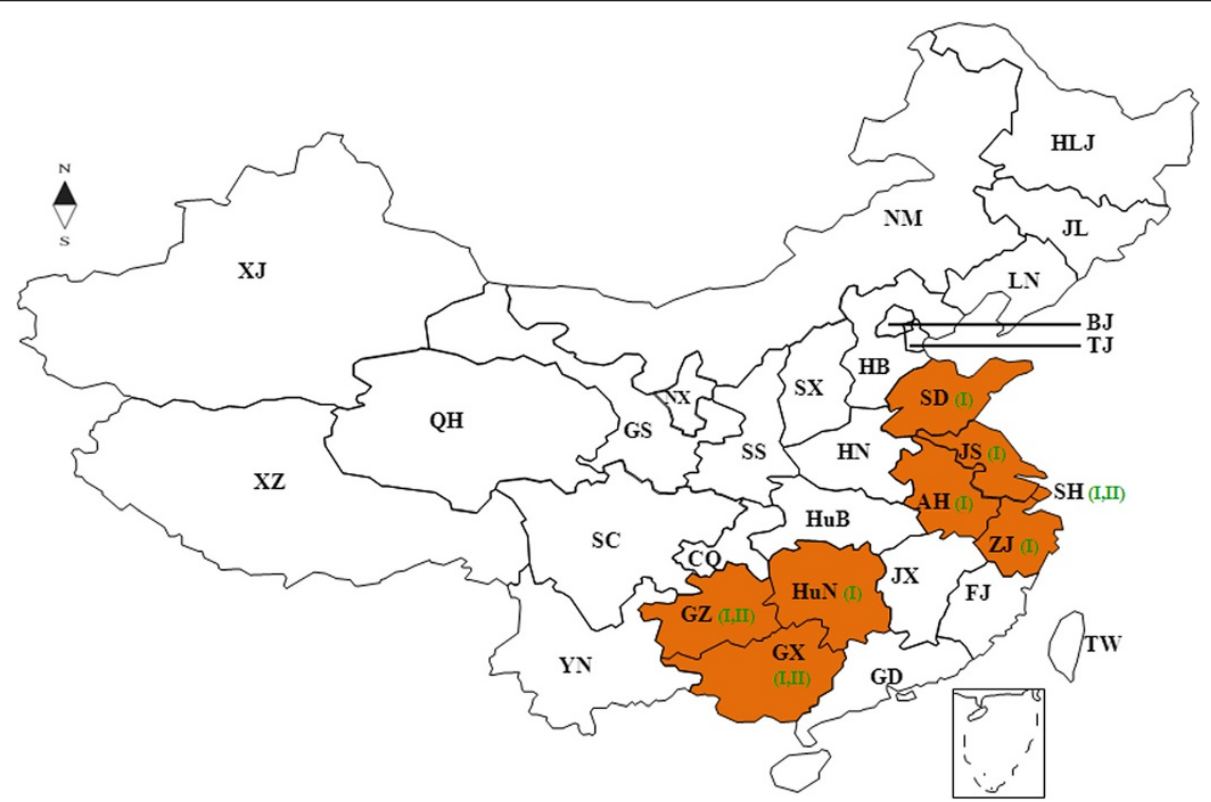

Figure 1 Locations of specimen collection in this study. AH, GX, GZ, HuN, JS, SD, SH, ZJ, indicate Anhui, Guangxi, Guizhou, Hunan, Jiangsu, Shandong, Shanghai, Zhejiang provinces of China, where the specimen were collected in this study during 2003 to 2008. I and II indicate the presence of isolates corresponding to Clade I and II as classified by the phylogenetic tree. 
Table 1 Background information of $P$ gene sequences used in this study

\begin{tabular}{|c|c|c|c|c|c|c|c|c|c|}
\hline Genus/isolates & Host & Origin & Year & GenBank acc. no. & Genus/isolates & Host & Origin & Year & GenBank acc. no. \\
\hline AH8 & Dog & $\mathrm{AH}$ & 2005 & HM582562 & $\mathrm{SH} 9$ & Dog & $\mathrm{SH}$ & 2004 & HM582564 \\
\hline AH12 & Dog & $\mathrm{AH}$ & 2005 & HM582567 & SH15 & Dog & $\mathrm{SH}$ & 2004 & HM582555 \\
\hline GX0801 & Dog & GX & 2008 & HM582588 & SH16 & Dog & $\mathrm{SH}$ & 2004 & HM582584 \\
\hline GX0802 & Dog & GX & 2008 & HM582589 & SH17 & Dog & $\mathrm{SH}$ & 2004 & HM582554 \\
\hline GX0803 & Dog & GX & 2008 & HM582590 & SH19 & Dog & $\mathrm{SH}$ & 2004 & HM582550 \\
\hline GX0804 & Dog & GX & 2008 & HM582591 & $\mathrm{SH} 2 \mathrm{O}$ & Dog & $\mathrm{SH}$ & 2004 & HM582532 \\
\hline GX0805 & Dog & GX & 2008 & HM582592 & SH24 & Dog & $\mathrm{SH}$ & 2003 & HM582536 \\
\hline GX0806 & Dog & GX & 2008 & HM582593 & $\mathrm{SH} 25$ & Dog & $\mathrm{SH}$ & 2003 & HM582553 \\
\hline GX0807 & Dog & GX & 2008 & HM582594 & SH27 & Dog & $\mathrm{SH}$ & 2003 & HM582529 \\
\hline GX0809 & Dog & GX & 2008 & HM582595 & SH28 & Dog & $\mathrm{SH}$ & 2003 & HM582524 \\
\hline$G \times 1$ & Dog & GX & 2006 & HM582521 & SH29 & Dog & $\mathrm{SH}$ & 2003 & HM582548 \\
\hline$G X 2$ & Dog & $\mathrm{GX}$ & 2006 & HM582546 & SH3O & Dog & $\mathrm{SH}$ & 2003 & HM582549 \\
\hline GX3 & Dog & GX & 2006 & HM582525 & SH31 & Dog & $\mathrm{SH}$ & 2003 & HM582556 \\
\hline GX5 & Dog & $G X$ & 2006 & HM582571 & SH32 & Dog & $\mathrm{SH}$ & 2003 & HM582561 \\
\hline$G X 6$ & Dog & $G X$ & 2006 & HM582581 & $D 03$ & Dog & ZJ & 2008 & HM582568 \\
\hline$G X 7$ & Dog & GX & 2006 & HM582526 & $D 05$ & Dog & ZJ & 2008 & HM582569 \\
\hline GX8 & Dog & GX & 2005 & HM582522 & $D 06$ & Dog & ZJ & 2008 & HM582573 \\
\hline$G X 9$ & Dog & GX & 2006 & HM582535 & $D 07$ & Dog & ZJ & 2008 & HM582570 \\
\hline GX10 & Dog & GX & 2005 & HM582523 & $D 10$ & Dog & ZJ & 2008 & HM582586 \\
\hline GX16 & Dog & GX & 2005 & HM582538 & F03 & CFB & ZJ & 2008 & HM582587 \\
\hline GX18 & Dog & GX & 2006 & HM582527 & CGX0521 & Dog & GX & 2005 & EU004759 \\
\hline GX19 & Dog & GX & 2006 & HM582543 & CGX0603 & Dog & GX & 2006 & EU004755 \\
\hline$G \times 24$ & Dog & GX & 2005 & HM582547 & CGX0614 & Dog & GX & 2006 & EU004758 \\
\hline GX26 & Dog & GX & 2006 & HM582528 & CHdg18 & Dog & GX & 2007 & AB458796 \\
\hline$G Z 1$ & Dog & $\mathrm{GZ}$ & 2005 & HM582580 & GX4 & Dog & GX & 1994 & GU358653 \\
\hline$G Z 3$ & Dog & $\mathrm{GZ}$ & 2005 & HM582544 & HN10 & Human & $\mathrm{HN}$ & 2006 & EU643590 \\
\hline GZ6 & Dog & $\mathrm{GZ}$ & 2005 & HM582579 & CHN0635 & Human & $\mathrm{HN}$ & 2006 & EU004777 \\
\hline$G Z 8$ & Dog & $\mathrm{GZ}$ & 2005 & HM582531 & CJS0523 & Dog & JS & 2005 & EU004782 \\
\hline$G Z 9$ & Dog & $\mathrm{GZ}$ & 2005 & HM582540 & JX08-45 & CFB & $J X$ & 2008 & GU647092 \\
\hline GZ10 & Dog & $\mathrm{GZ}$ & 2005 & HM582541 & NeiMeng925 & Dog & NM & 2008 & FJ415313 \\
\hline GZ11 & Dog & $\mathrm{GZ}$ & 2005 & HM582562 & SHOG & Dog & $\mathrm{SH}$ & 2006 & GU345748 \\
\hline GZ12 & Dog & $\mathrm{GZ}$ & 2005 & HM582545 & $\mathrm{SH} 26$ & Dog & $\mathrm{SH}$ & 2003 & HM582583 \\
\hline GZ13 & Dog & $\mathrm{GZ}$ & 2005 & HM582537 & D01 & Dog & ZJ & 2008 & FJ712193 \\
\hline GZ14 & Dog & $\mathrm{GZ}$ & 2005 & HM582551 & D02 & Dog & ZJ & 2008 & FJ712194 \\
\hline GZ15 & Dog & $\mathrm{GZ}$ & 2005 & HM582552 & D04 & Dog & ZJ & 2008 & FJ032321 \\
\hline GZ16 & Dog & $\mathrm{GZ}$ & 2005 & HM582534 & D08 & Dog & ZJ & 2008 & FJ032322 \\
\hline GZ17 & Dog & $\mathrm{GZ}$ & 2005 & HM582530 & F02 & CFB & ZJ & 2008 & FJ712195 \\
\hline GZ21 & Dog & $\mathrm{GZ}$ & 2008 & HM582572 & 8743THA & Human & Thailand & 1983 & EU293121 \\
\hline HN4 & Dog & $\mathrm{HuN}$ & 2005 & HM582519 & 8764THA & Human & Thailand & 1983 & EU293111 \\
\hline HN27 & Dog & HuN & 2005 & HM582582 & INRV & Human & India & 2005 & AY956319 \\
\hline HN29 & Dog & HuN & 2005 & HM582520 & NNV-RAB-H & Human & India & 2006 & EF437215 \\
\hline HN3O & Dog & HuN & 2005 & HM582542 & CVS & Challenge virus standard & & & $\times 55727$ \\
\hline$J S 29$ & Dog & JS & 2006 & HM582563 & $\mathrm{aG}$ & Vaccine st rain & China & & DQ646875 \\
\hline$J S 34$ & Dog & JS & 2006 & HM582565 & CTN & Vaccine st rain & China & & FJ959397 \\
\hline
\end{tabular}


Table 1 Background information of $\mathbf{P}$ gene sequences used in this study (Continued)

\begin{tabular}{|c|c|c|c|c|c|c|c|c|c|}
\hline$S D 1$ & Dog & SD & 2008 & HM582557 & PV & Vaccine st rain & France & & M13215 \\
\hline$S D 7$ & Dog & SD & 2007 & HM582559 & SADB19 & Vaccine st rain & USA & & M31046 \\
\hline SD8 & Dog & SD & 2007 & HM582558 & $\mathrm{Ni}-\mathrm{CE}$ & Vaccine st rain & Japan & & AB128149 \\
\hline SD10 & Dog & SD & 2007 & HM582533 & $\mathrm{RC}-\mathrm{HL}$ & Vaccine st rain & Japan & & AB009663 \\
\hline SD11 & Dog & SD & 2007 & HM582575 & Flury-HEP & Vaccine st rain & USA & & GU565704 \\
\hline SD12 & Dog & SD & 2007 & HM582574 & 8619NGA & Bat & Nigeria & 1956 & EU293110 \\
\hline SD13 & Dog & SD & 2007 & HM582576 & MOKV & Cat & Zimbabwe & 1981 & NC006429 \\
\hline SD14 & Dog & SD & 2006 & HM582577 & $86132 S A$ & Human & South Africa & 1971 & EU293119 \\
\hline$S D 23$ & Dog & SD & 2008 & HM582578 & 8918FRA & Bat & France & 1989 & EU293112 \\
\hline SH1 & Dog & $\mathrm{SH}$ & 2005 & HM582585 & $9018 \mathrm{HOL}$ & Bat & Netherlands & 1986 & EU293114 \\
\hline SH5 & Dog & $\mathrm{SH}$ & 2005 & HM582566 & ABLV & Bat & Aust ralia & 1996 & NC003243 \\
\hline SH7 & Dog & $\mathrm{SH}$ & 2004 & HM582560 & $W C B V$ & Bat & Russia & 2002 & EF614258 \\
\hline
\end{tabular}

Note: New sequences in this study are labeled Bold and italic; AH, GX, GZ, HuN, JS, JX, NM, SD, SH, ZJ, indicate Anhui, Guangxi, Guizhou, Hunan, Jiangsu, Jiangxi, Inner Mongolia, Shandong, Shanghai, Zhejiang provinces of China, respectively; CFB: Chinese Ferret Badgers.

nucleotide and amino acid sequence identities of the $\mathrm{P}$ gene were $80.2-100 \%$ and $85.2-100 \%$ respectively. When compared with the vaccine strains, the $\mathrm{P}$ gene of the 77 Chinese RABVs had 85.0-99.2\% (80.0-89.5\%) amino acid (nucleotide) identity, respectively.

\section{Variation of functionally significant sequence motifs and residues}

Based on the identity analysis, an amino acid alignment of the 77 Chinese RABVs isolates and representative sequences of laboratory and vaccine strains was generated and investigated for mutations (Figure 2). In total, seventy two amino acid substitutions throughout the $\mathrm{P}$ protein were observed in the Chinese RABVs isolates relative to the PV vaccine strain (M13215). Based on the location of the mutations, the protein had both highly conserved and highly variable regions that have been previously shown to be associated with viral function. Specifically, there were two conserved domains at residues 1-50 (CD1) and 184-279 (CD2) and two variable domains at residues 51-80 (VD1) and 126-178 (VD2) (Figure 2). The first 19 aa residues at the $\mathrm{N}$-terminal, shown to be associated with L binding [10], are completely conserved. The short lysine-rich segment FSKKYKF (209-216aa) thought to be an important component of the $\mathrm{C}$-terminal $\mathrm{N}$ protein binding domain [14], is also highly conserved in all Chinese isolates. Within region VD2, the cytoplasmic dynein LC8 binding motif (K/R) XTQT [18] is conserved with Chinese RABVs, and all the strains contain the motif KSTQT (located between 144 and 148 aa). Interestingly, the STAT-1 binding sites, located in the last 30 aa residues of the C-terminal [20] showed limited conservation in Chinese isolates. The internal translation initiation sites 20,53, 69, and 83 in the $\mathrm{P}$ protein of the rabies challenge virus standard (CVS) strain [24] are at the same position in the Chinese RABVs isolates. Three of them $\left(\mathrm{Met}_{20}, \mathrm{Met}_{53}\right.$, and $\left.\mathrm{Met}_{83}\right)$ are completely conserved in Chinese RABVs. For the remainder, the mutation Met $_{69}$ toVal $_{69}$ occurred in isolate GZ8 and mutation Met $_{69}$ to Ala $_{69}$ occurred in isolates HN29, GX0802, GZ7, GX16. Four $\left(\operatorname{Ser}_{64}, \operatorname{Ser}_{162}, \operatorname{Ser}_{210}, \operatorname{Ser}_{271}\right)$ of five serine residues reported to function as phosphate acceptors in the $\mathrm{P}$ protein of the rabies challenge virus standard (CVS) strain [9] were absolutely conserved. For the fifth residues mutation $\mathrm{Ser}_{63}$ to $\mathrm{Phe}_{63}$ or $\mathrm{Ser}_{63}$ to $\mathrm{Leu}_{63}$ was observed in all the Chinese isolates with the exception of isolate $\mathrm{SH} 19$.

\section{Phylogenetic analysis of RABVs in China}

A phylogenetic analysis of 113 (77 collected in this study, with an additional 36 samples downloaded from GenBank) RABV P gene sequences was performed. The Neighbor-joining tree is shown in Figure 3 with bootstrap values shown for the main groupings. The sequences of Chinese isolates were divided into two major clades, named clade I and II (Figure 3). Most of the 77 isolates collected in this study are placed in Clade I (bootstrap value $=98$ ). These isolates are mainly from Anhui, Guangxi, Guizhou, Hunan, Jiangsu, Shandong, Shanghai and Zhejiang provinces, and show a close evolutionary history with the RABVs isolates from Thailand (8764THA, EU293111; 8743THA, EU293121). Clade II (bootstrap value $=98$ ) are composed of isolates from Shanghai, Guizhou and Guangxi provinces, are grouped with the standard challenge strain (CVS) and vaccine strains (aG, PV, RC HL, SADB19, Ni-CE and FluryHEP), and show a close relationship to arctic-related RABVs strains from India and northeastern China (Inner Mongolia). Chinese Ferret badger strain F03 was grouped with D10 strain isolated from dog in the same location, indicating that RABVs spillover can occur between dogs and Chinese Ferret badgers. 


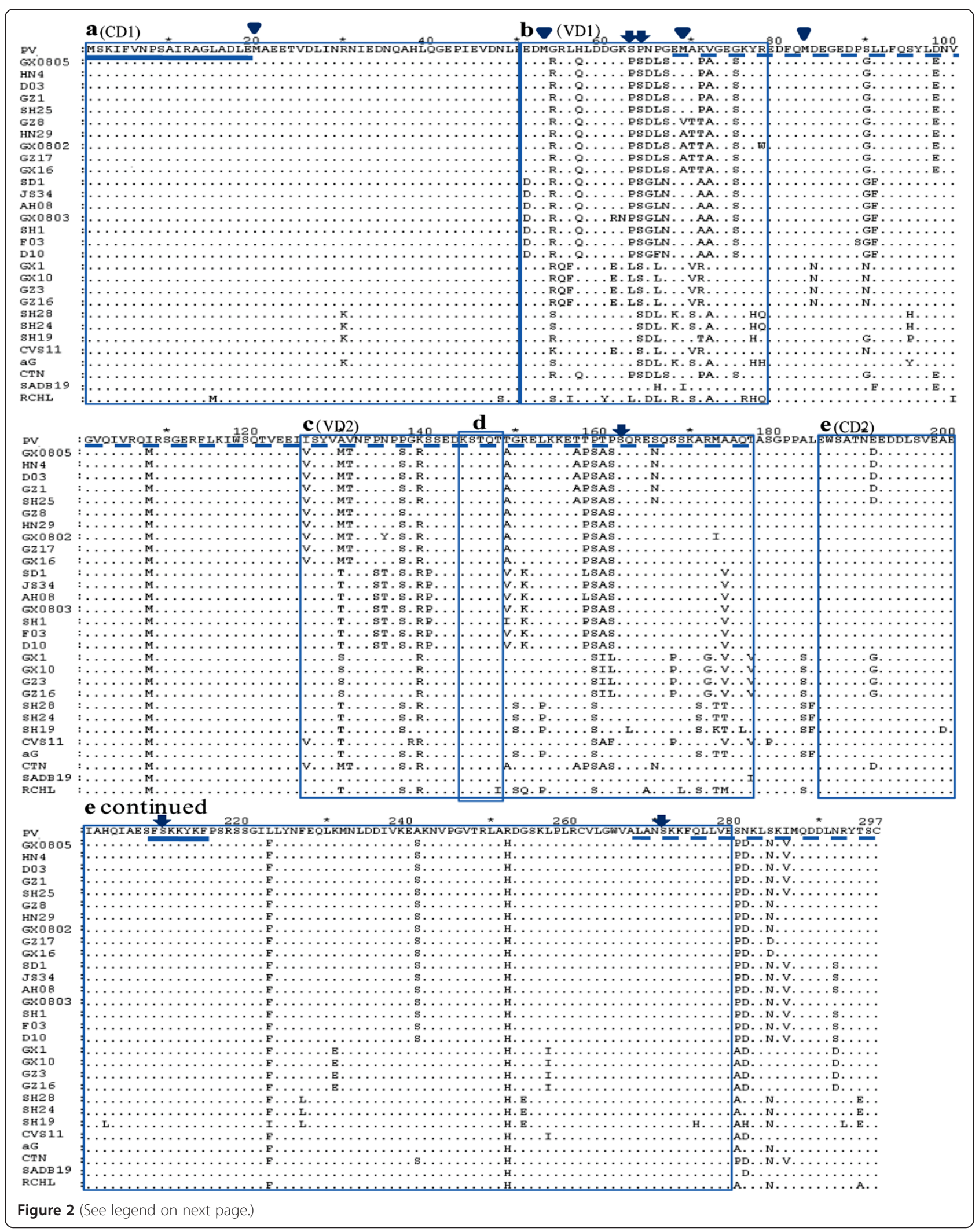


(See figure on previous page.)

Figure 2 Alignment of the $P$ amino acid sequences of street strains collected in this study, vaccine strains and standard challenge virus strain CVS11. Dots indicate amino acids that are in agreement with the reference sequence (PV vaccine strain (M13215)) on the first line. Box $\mathbf{a}$ and $\mathbf{e}$ : conserved domains 1 and 2; box $\mathbf{b}$ and $\mathbf{c}$ : variable domains 1 and 2; box $\mathbf{d}$ : Dynein light chain (LC8)-binding motif; solid underline shows $L$ protein binding region(1-19 aa) and the lysine-rich motif (209-216 aa), respectively; dashed underline shows $N$ protein binding site; triangles indicate the positions of methionine residues and confirmed translation initiation in the CVS strain; arrows indicate the positions of serine residues identified as phosphoacceptors in the P protein of the CVS strain.

\section{Substitution rates and evolution history analysis of $\mathrm{P}$ gene}

By using a Bayesian Markov chain Monte Carlo method, the evolutionary history, including evolutionary rates of populations (nucleotide substitutions per site per year) and TMRCA (the most recent common ancestor) were analyzed based on $58 \mathrm{P}$ gene sequences (Only sequences with an homology less than $98 \%$ and with full background information in terms of location and isolation time were used in the calculation). The estimated mean rate of nucleotide substitution for the P gene of Chinese RABVs was $3.305 \times 10^{-4}$ substitutions per site per year (95\% HPD values, $1.127-6.209 \times 10^{-4}$ substitutions per site per year).
Bayesian coalescent analysis estimated the most recent common ancestor (TMRCA) to have originated 592 years ago (95\% HPD, 142-2621 years) (Figure 4).

\section{Discussion and conclusion}

The $\mathrm{N}$ gene (the most conserved and abundant mRNA in infected cells) and G gene (plays a crucial role in viral neurotropism and pathogenicity) have been widely targeted for genetic, molecular epidemiology and evolutionary analysis of RABVs [4,25-28]. In contrast, for the P gene, only a few laboratory $[29,30]$ and wild-type RABV strains [31], an ABLV isolate [32] and Mokola virus [33] have been genetically characterized. In this study we

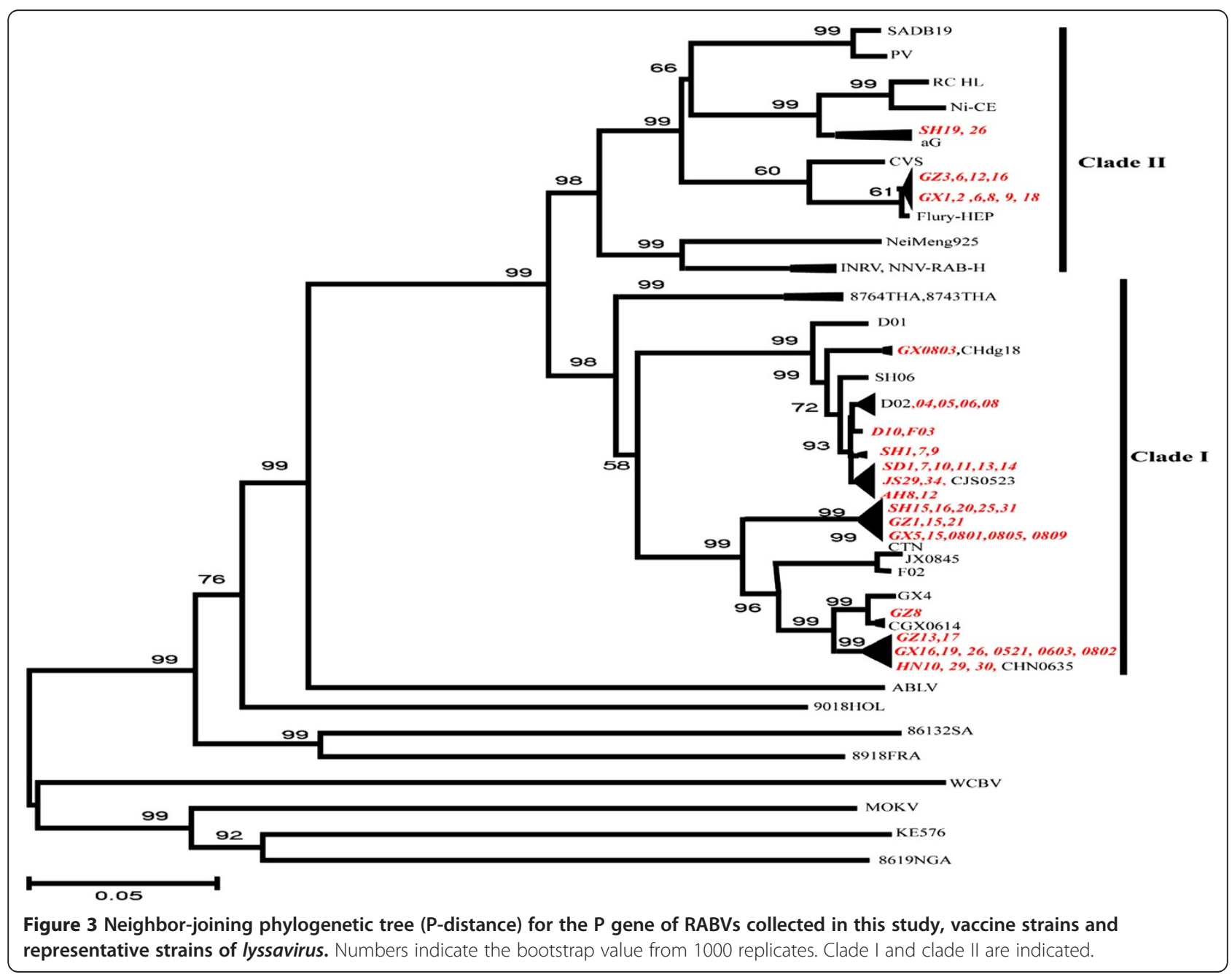




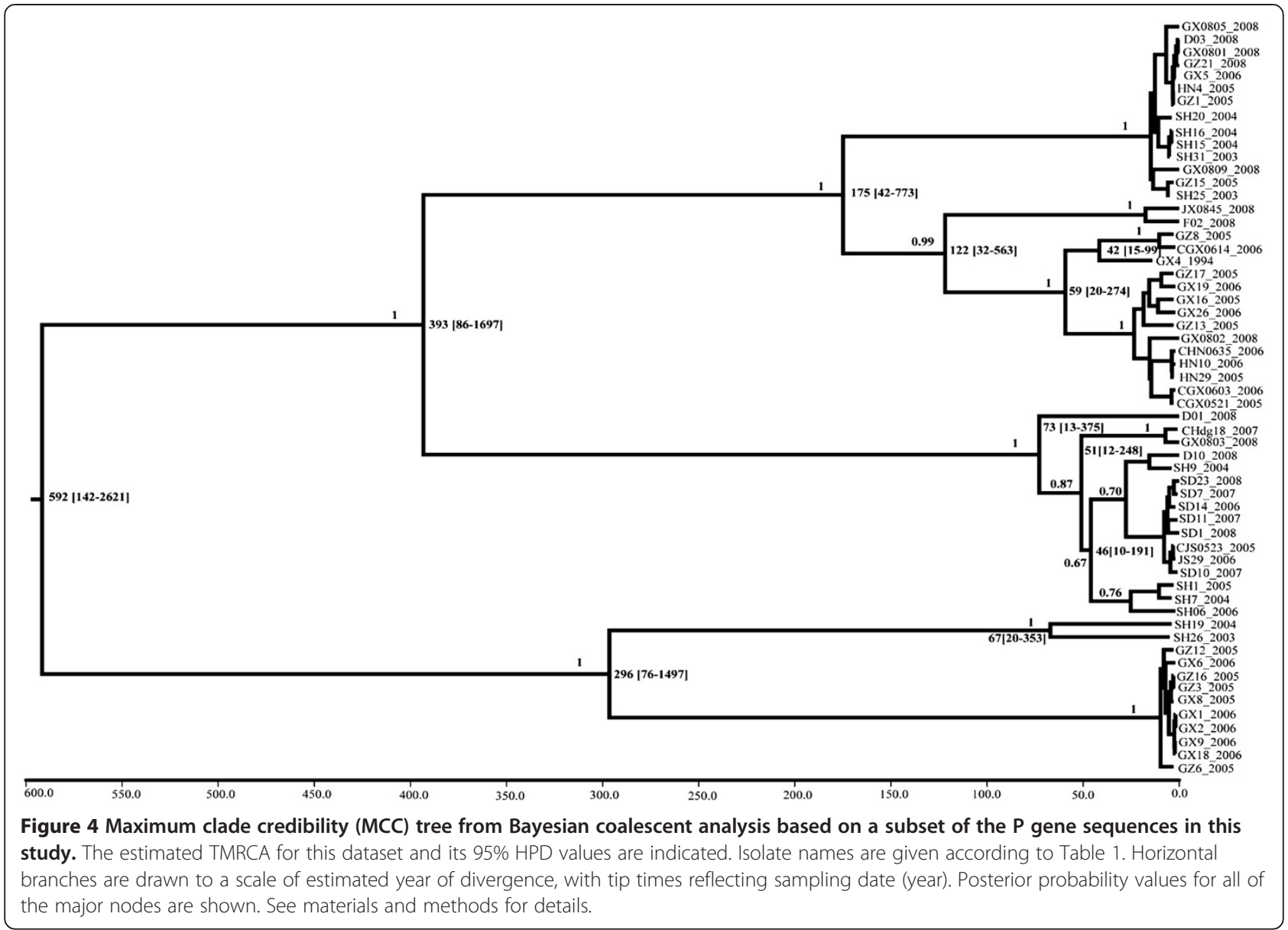

attempted to characterize the genetic and evolutionary properties of the $\mathrm{P}$ gene of Chinese street RABVs. $77 \mathrm{P}$ genes from brain samples of dogs and wild animals in eight provinces through 2003 to 2008 were sequenced and subjected to molecular and phylogenetic analysis.

Several substitutions were found in the Chinese RABVs strains compared to the laboratory adapted and vaccine strains. The nucleotide $(\geq 80.2 \%)$ and amino acid sequence identities $(\geq 85.2)$ of the $\mathrm{P}$ gene were lower than the corresponding values for the $\mathrm{N}(\geq 87.6 \%$ and $95.4 \%)$ and $\mathrm{G}$ gene ( $\geq 87 \%$ and $93.8 \%)[26,28]$. Consistent with the wild type RABVs strains isolated in North America [31], two conserved $(\mathrm{CD} 1,2)$ and two variable $(\mathrm{VD} 1,2)$ domains were identified in Chinese RABVs. The observed substitutions are mainly located in the middle of $\mathrm{P}$, while the $\mathrm{N}$ and $\mathrm{C}$ terminal are relatively well conserved. As reported previously, the need to retain overall negative charge rather than primary sequence would explain the VD1 region's high level of diversity [6]. The poorly conserved VD2 might indicate a function as a spacer/hinge segment analogous to the hinge region of the $\mathrm{P}$ gene in Vesicular stomatitis virus (VSV) located between two functionally important domains [34]. Two sequence motifs, one believed to confer binding to the cytoplasmic dynein light chain LC8, and a lysinerich sequence probably contributing to $\mathrm{N}$ protein binding [14], were conserved throughout Chinese RABVs samples, while the STAT-1 binding sites [20], internal translation initiation sites and phosphate acceptor sites showed different degrees of variation. Whether these variations could affect the biological characteristics of Chinese RABVs need to be further investigated.

There have been several previous estimates of RABVs substitution rates for the G gene (1.2-6.5 $\times 10^{-4}$ substitutions per site per year) and the N gene (1.1-5.6 $\times 10^{-4}$ substitutions per site per year) based on dog, fox and mongoose RABVs samples collected worldwide [25,27,35-38]. In this study, Bayesian coalescent analysis showed that mean substitution rate of the $\mathrm{P}$ gene for the Chinese RABVs isolates is $3.305 \times 10^{-4}$ substitutions per site per year, which indicates that the genome RNA of RABVs circulating worldwide is stable. The TMRCA of cosmopolitan canine RABV variants has previously been estimated to be between 284 and 504 years ago [39]. The mean divergence time estimated based on the the $G$ gene is 583 years ago for RABVs circulating globally [25,35], and 596 years ago for RABVs for current Chinese RABVs [27]. Using a similar 
analysis, we estimated the average TMRCA of RABVs circulating in China based on the P gene to be 592 years ago, which was in accordance with previous reports for RABVs.

Previous phylogenetic studies based on the $\mathrm{G}$ and $\mathrm{N}$ genes $[26,28,39,40]$ showed that RABVs in China can be classified into distinct clades or groups. The phylogenetic analysis in this report based on the P gene revealed that Chinese RABVs could be divided into two distinct clades, and that isolates from more than one clade RABV variants are currently co-circulating in the same Chinese provinces. Also, RABVs in Clades I are grouped with RABVs from Thailand, and RABVs in clade II are grouped with RABVs from India. The topology of the phylogenetic tree based on the P gene is similar to the $G$ and $N$ gene trees $[26,28,39,40]$. This indicates that the P, G and N genes are equally valid for examining the phylogenetics of RABVs and is consistent with observations that the N, P, $\mathrm{M}, \mathrm{G}$ and $\mathrm{L}$ genes of RABVs interact and evolve in a cooperative manner to effect virus infection and evolution $[41,42]$.

\section{Methods}

\section{Viral specimens sampling}

Brain specimens were collected as part of a national surveillance program from dogs used as meat in restaurants and from suspected rabid Ferret badgers from eight provinces (Anhui, Guangxi, Guizhou, Hunan, Jiangsu, Shandong, Shanghai and Zhejiang) in China from 2003 to 2008 (Figure 1).

\section{Detection and sequencing of RABV}

All specimens were examined by using a direct immune fluorescence assay (DFA) [26] with a fluorescent-labeled monoclonal antibody against the RABV N protein (Rabies DFA Reagent; Chemicon Europe Ltd., Chandlers Ford, UK). For all identified RABV specimens, RNA was extracted from tissue of rabies-infected brains $(0.1 \mathrm{~g})$ with TRIzol Reagent (Invitrogen, Carlsbad, CA, USA) and used as template for cDNA synthesis with Ready-To-Go YouPrime First-Strand Beads (Amersham Pharmacia Bioscience, Chalfont St. Giles, UK) and a rabies $P$ gene specific primer: Pfor 5'-GAACCATCCCAAAYATG AG -3' (corresponding to bases 1500-1519 of the positive sense genome sequence of the PV strain). The ORF sequence of the $\mathrm{P}$ gene, encoding regions corresponding to bases 1514 to 2407 of the total genetic sequence of the PV strain, was amplified with primers Pfor and Prev 5'- CTATCTTGCG CAGAAARTTCAT -3' (corresponding to bases 2496 to 2517 of the positive sense genome sequence of the PV strain). PCR products were purified by using the QIAquick PCR Purification Kit (QIAGEN Ltd., Crawley,UK) and sequenced with an ABI PRISM 3100 DNA sequencer (Applied Biosystems, Foster City, CA, USA).

\section{Sequence alignment and phylogenetic analysis}

$\mathrm{P}$ gene sequences of lyssaviruses deposited in GenBank were downloaded and combined with the newly sequenced samples to form the dataset used in this study. Alignment of nucleotide sequences and deduced amino acid sequence were performed by using the ClustalX program, version 2.1 [43]. Genetic identities were determined using the BioEdit program [44] and MegAlign software version 5 (DNAStar, Inc., Madison,WI, USA). Phylogenetic and evolutionary analyses were conducted using Mega 3.1 [45]. Neighbor-joining (NJ) phylogenetic trees were constructed using evolutionary distance correction statistics $[46,47]$. Bootstrap analysis was performed using 1000 replications and values greater than $70 \%$ were regarded as strong evidence for particular phylogenetic groupings.

\section{Bayesian Markov chain Monte Carlo (MCMC) evolutionary analysis}

Evolutionary history, including evolutionary rates of populations (nucleotide substitutions per site per year) and TMRCA (the most recent common ancestor) were inferred by using the Bayesian Markov chain Monte Carlo (MCMC) method available in the BEAST software package (http://beast.bio.ed.ac.uk/Main_Page) [48]. Briefly, an input file for BEAST was generated by using the BEAUti program with sequences dated according to the year of isolation. Sequences with homology greater than 98\% were removed from the analysis using TCOFFEE. The best-fit model of nucleotide substitution for Bayesian analysis was selected with Modeltest 3.7 [49]. The general time reversible (GTR) substitution model, incorporating a proportion of invariable sites (I) and a gamma distribution of rate variation among sites (C4) was used for the BEAST analysis. Both strict and relaxed (uncorrelated exponential and lognormal) molecular clocks [50] were considered to explore the extent of variation in the rate of nucleotide substitution. The BEAST output was assessed using the TRACER program. The maximum clade credibility (MCC) tree was generated using Figtree (available from http://beast.bio.ed.ac.uk).

\section{Competing interests}

The authors declare that they have no competing interests.

\section{Authors' contributions}

LHW did genetic mutation, phylogenetic and evolution analysis and drafted the manuscript; HW carried out nucleic acid detection and sequencing; XYT and $\mathrm{HL}$ participated in the collection of samples; SR participated the genetic mutation, phylogenetic and evolution analysis; GDL participated in the design of experiments; QT conceived of the study, and participated in its design and coordination. All authors read and approved the final manuscript.

\section{Authors' information}

Dr. Lihua Wang, Ph.D., is an associate professor at the State Key Laboratory for Infectious Disease Prevention and Control, the Institute for Viral Disease Control and Prevention, Chinese Center for Disease Control and Prevention. His current research focuses on molecular epidemiology of Rabies virus, development reverse genetic system of rabies virus and basic research related to rabies. 


\section{Acknowledgements}

We thank the staffs of the provincial CDCs (Anhui, Guangxi, Guizhou, Hunan, Jiangsu, Shandong, Shanghai and Zhejiang) for helping with field investigations and sample collection.

This work was supported by the National Department Public Benefit Research Foundation (200803014), Major Program of National Natural Science Foundation of China (30630049), Key Technologies Research and Development Program of China (2009ZX10004-705) and Grant from NIID (National Institute of Infectious Diseases, Japan).

\section{Author details}

'State Key Laboratory for Infectious Disease Prevention and Control, Institute for Viral Disease Control and Prevention, Chinese Center for Disease Control and Prevention, 155 Changbai St., Changping Dist, Beijing 102206, China. ${ }^{2}$ State Key Laboratory for Virology, Wuhan Institute of Virology, Chinese Academy of Sciences, Hubei 430071, China.

Received: 28 June 2012 Accepted: 7 December 2012 Published: 7 January 2013

\section{References}

1. International Committee on Taxonomy of Viruses: ICTV files and discussions. ICTV master species list. 2009. Version 4. http://talk.ictvonline.org/files/ ictvdocuments $/ \mathrm{m} / \mathrm{ms} / 1231$.aspx (accessed 02.06.10).

2. Tang XC, Luo M, Zhang SY, Anthony RF, Hu RL: Pivotal role of dogs in rabies transmission, China. Emerg Infect Dis 2005, 11(12):1970-1972.

3. Hu RL, Tang Q, Tang JR, Fooks AR: Rabies in China: an update. Vector Borne Zoonotic Dis 2009, 9(1):1-11.

4. Delmas O, Holmes EC, Talbi C, Larrous F, Dacheux L, Bouchier C, Bourhy H: Genomic diversity and evolution of the lyssaviruses. PLoS One 2008, 303(4):e2057.

5. Le MP, Jacob $Y$, Tordo $N$ : The complete Mokola virus genome sequence: structure of the RNA-dependent RNA polymerase. J Gen Virol 1997, 78:1571-1576

6. Nadin-Davis SA, Abdel-Malik M, Armstrong J, Wandeler Al: Lyssavirus P gene characterisation provides insights into the phylogeny of the genus and identifies structural similarities and diversity within the encoded phosphoprotein. Virology 2002, 298(2):286-305.

7. Gerard FC, Ribeiro EAJ, Leyrat C, Ivanov I, Blondel D, Longhi S, Ruigrok RW, Jamin M: Modular organization of rabies virus phosphoprotein. J Mol Biol 2009, 388(5):978-996.

8. Schnell MJ, McGettigan JP, Wirblich C, Papaneri A: The cell biology of rabies virus: using stealth to reach the brain. Nat Rev Microbiol 2010, 8(1):51-61.

9. Gupta AK, Blondel D, Choudhary S: The phosphoprotein of rabies virus is phosphorylated by a unique celluar protein kinase and specific isomers of protein kinase C. Virology 2000, 74(1):91-98

10. Chenik M, Schnell M, Conzelmann KK, Blondel D: Mapping the interacting domains between the rabies virus polymerase and phosphoprotein. J Virol 1998, 72:1925-1930.

11. Fu ZF, Zheng $\mathrm{Y}$, Wunner WH: Both the $\mathrm{N}$ and $\mathrm{C}$ - terminal domains of the nominal phosphoprotein of rabies virus are involved in binding to the nucleoprotein. Virology 1994, 200(2):590-597.

12. Mavrakis M, Méhouas S, Réal E, Iseni F, Blondel D, Tordo N, Ruigrok RW: Rabies virus chaperone: identification of the phosphoprotein peptide that keeps nucleoprotein soluble and free from non-specific RNA. Virology 2006, 349(2):422-429

13. Green TJ, Macpherson S, Qiu S, Lebowitz J, Wertz GW, Luo M: Study of the assembly of vesicular stomatitis virus $\mathrm{N}$ protein: role of the $\mathrm{P}$ protein. J Virol 2000, 74:9515-9524.

14. Jacob Y, Real E, Tordo N: Functional interaction map of lyssavirus phosphoprotein: identification of the minimal transcription domains. J Virol 2001, 75:9613-9622

15. Schoehn G, Iseni F, Mavrakis M, Blondel D, Ruigrok RWH: Structure of recombinant rabies virus nucleoprotein-RNA complex and identification of the phosphoprotein binding site. J Virol 2001, 75:490-498.

16. Jacob Y, Badrane H, Ceccaldi PE, Tordo N: Cytoplasmic dynein LC8 interacts with lyssavirus phosphoprotein. J Virol 2000, 74:10217-10222.

17. Raux H, Flamand A, Blondel D: Interaction of the rabies virus P protein with the LC8 dynein light chain. J Virol 2000, 74:10212-10216.
18. Lo KW, Naisbitt S, Fan JS, Sheng M, Zhang M: The 8-kDa dynein light chain binds to its targets via a conserved (K/R)XTQT motif. J Biol Chem 2001, 276:14059-14066.

19. Brzozka K, Finke $\mathrm{S}$, Conzelmann KK: Identification of the rabies virus alpha/ beta interferon antagonist: phosphoprotein $\mathrm{P}$ interferes with phosphorylation of interferon regulatory factor 3. J Virol 2005, 79:7673-7681.

20. Vidy A, Chelbi-Alix MK, Blondel D: Rabies virus P protein interacts with STAT1 and inhibits interferon signal transduction pathways. J Virol 2005, 79:14411-14420

21. Vidy A, Bougrini J, Chelbi-Alix MK, Blondel D: The nucleocytoplasmic rabies virus $\mathrm{P}$ protein counteracts interferon signaling by inhibiting both nuclear accumulation and DNA binding of STAT1. J Virol 2007, 81:4255-4263.

22. Bernardi R, Pandolfi PP: Structure, dynamics and functions of promyelocytic leukaemia nuclear bodies. Nature Rev Mol Cell Biol 2007, 8:1006-1016.

23. Blondel $\mathrm{D}$, Kheddache $\mathrm{S}$, Lahaye $\mathrm{X}$, Dianoux L, Chelbi-Alix MK: Resistance to rabies virus infection conferred by the PMLIV isoform. $J$ Virol 2010 , 84(20):10719-10726.

24. Chenik M, Chebli K, Blondel D: Translation initiation at alternate in-frame AUG codons in the rabies virus phosphoprotein $\mathrm{mRNA}$ is mediated by a ribosomal leaky scanning mechanism. J Virol 1995, 69:707-712.

25. Bourhy H, Reynes JM, Dunham EJ, Dacheux L, Larrous F, Huong VT, Xu G, Yan J, Miranda ME, Holmes EC: The origin and phylogeography of dog rabies virus. J Gen Virol 2008, 89:2673-2681.

26. Tao XY, Tang Q, Li H, Mo ZJ, Zhang H, Wang DM, Zhang Q, Song M, Velasco-Villa A, Wu XF, Rupprecht CE, Liang GD: Molecular epidemiology of rabies in southern People's Republic of China. Emerg Infect Dis 2009, 15:1992-1998

27. Ming PG, Yan JX, Simon R, Meng SL, Xu GL, Tang Q, Wu J, Luo J, Yang XM: A history estimate and evolutionary analysis of rabies virus variants in China. J Gen Virol 2010, 91:759-764.

28. Meng SL, Yan JX, Xu GL, Nadin-Davis SA, Ming PG, Liu SY, Ming HT, Zhu FC, Zhou DJ: A molecular epidemiological study targeting the glycoprotein gene of rabies virus isolates from China. Virus Res 2007, 124:125-138

29. Conzelmann K, Cox JH, Schneider LG, Thiel H: Molecular cloning and complete nucleotide sequence of the attenuated rabies virus SAD B19. Virology 1990, 175:485-499.

30. Larson JK, Wunner WH: Nucleotide and deduced amino acid sequences of the nominal nonstructural phosphoprotein of the ERA, PM and CVS-11 strains of rabies virus. Nucleic Acids Res 1990, 18(23):7172.

31. Nadin-Davis S, Huang W, Wandeler Al: Polymorphism of rabies viruses within the phosphoprotein and matrix protein genes. Arch Virol 1997, 142:1-14.

32. Gould A, Hyatt AD, Lunt R, Kattenbelt JA, Hengstberger S, Blacksell SD: Characterisation of a novel lyssavirus isolated from pteropid bats in Australia. Virus Res 1998, 54:165-187.

33. Bourhy H, Bachir K, Tordo N: Molecular diversity of the Lyssavirus genus. Virology 1993, 194:70-81.

34. Banerjee AK, Barik S: Gene expression of vesicular stomatitis virus genome RNA. Virology 1992, 188:417-428.

35. Gong WJ, Jiang Y, Zhang YF, Zeng Z, Shao MF, Fan JH, Sun YW, Xiong ZL, Yu XL, Tu CC: Temporal and spatial dynamics of rabies viruses in China and Southeast Asia. Virus Res 2010, 150:111-118.

36. Bourhy H, Kissi B, Audry L, Smreczak M, Sadkowska-Todys M, Kulonen K, Tordo N, Zmudzinski JF, Holmes EC: Ecology and evolution of rabies virus in Europe. J Gen Virol 1999, 80:2545-2557.

37. Davis PL, Bourhy H, Holmes EC: The evolutionary history and dynamics of bat rabies virus. Infect Genet Evol 2006, 6:464-473.

38. Talbi C, Holmes EC, de Benedictis P, Faye O, Nakoune E, Gamatie D, Diarra A, Elmamy BO, Sow A, Adjogoua EV, Sangare O, Dundon WG, Capua I, Sall AA, Bourhy H: Evolutionary history and dynamics of dog rabies virus in western and central Africa. J Gen Virol 2009, 90:783-791.

39. Badrane $\mathrm{H}$, Tordo $\mathrm{N}$ : Host switching in lyssavirus history from the Chiroptera to the Carnivora orders. J Virol 2001, 75:8096-8104.

40. Zhang $Y Z$, Xiong $C L$, Lin XD, Zhou DJ, Jiang RJ, Xiao QY, Xie XY, Yu XX, Tan YJ, Li M, Ai Q, Zhang L, Zou Y, Huang C, Fu ZF: Genetic diversity of Chinese rabies viruses: Evidence for the presence of two distinct clades in China. Infect Genet Evol 2009, 9:87-96.

41. Yamada K, Ito N, Takayama-Ito M, Sugiyama M, Minamoto N: Multigenic relation to the attenuation of rabies virus. Microbiol Immunol 2006, 50:25-32. 
42. Shimizu K, Ito N, Mita T, Yamada K, Hosokawa-Muto J, Sugiyama M, Minamoto N: Involvement of nucleoprotein, phosphoprotein, and matrix protein genes of rabies virus in virulence for adult mice. Virus Res 2007, 123:154-160.

43. Thompson JD, Gibson TJ, Plewniak F, Jeanmougin F, Higgins DG: The ClustalX windows interface: flexible strategies for multiple sequence alignment aided by quality analysis tools. Nucleic Acids Res 1997, 25:4876-4882.

44. Hall TA: BioEdit: a user-friendly biological sequence alignment editor and analysis program for Windows 95/98/NT. Nucleic Acids Symp 1999, 41:95-98.

45. Kumar S, Tamura K, Nei M: MEGA3: integrated software for molecular evolutionary genetics analysis and sequence alignment. Brief Bioinform 2004, 5:50-163.

46. Kimura M: A simple method for estimating evolutionary rates of base substitutions through comparative studies of nucleotide sequences. J Mol Evol 1980, 15:111-120.

47. Tajima F, Nei M: Estimation of evolutionary distance between nucleotide sequences. Mol Biol Evol 1984, 1:269-285.

48. Drummond AJ, Rambaut A: BEAST: Bayesian evolutionary analysis by sampling trees. BMC Evol Biol 2007, 7:214.

49. Posada D, Crandall KA: MODELTEST: testing the model of DNA substitution. Bioinformatics 1998, 14(9):817-818.

50. Drummond AJ, Ho SYW, Phillips MJ, Rambaut A: Relaxed phylogenetics and dating with confidence. PLoS Biol 2006, 4:e88.

doi:10.1186/1743-422X-10-14

Cite this article as: Wang et al:: Genetic and evolutionary

characterization of RABVs from China using the phosphoprotein gene. Virology Journal 2013 10:14.

\section{Submit your next manuscript to BioMed Central and take full advantage of:}

- Convenient online submission

- Thorough peer review

- No space constraints or color figure charges

- Immediate publication on acceptance

- Inclusion in PubMed, CAS, Scopus and Google Scholar

- Research which is freely available for redistribution 